\title{
APLIKASI PELAYANAN SERVIS AC MOBIL PADA ANDROMEDA BENGKULU
}

\author{
Indra Kanedi ${ }^{1}$, Siswanto ${ }^{2}$ \\ ${ }^{1,2}$ Jurusan Sistem Informasi, Fakultas Ilmu Komputer, Universitas Dehasen Bengkulu \\ Jl. Meranti Raya No.32 Sawah Lebar, Kota Bengkulu, 38228 \\ Email: indradehasen@yahoo.co.id, sisunived2017@gmail.com
}

\begin{abstract}
ABSTRAK
Aplikasi pelayan sevis AC mobil pada CV. Andromeda bengkulu dimana dalam proses kerja aplikasi pelayanan servis ini menggunakan bahasa pemrograman visual basic. 6.0. Metode yang dilakukan pada Aplikasi Pelayanan Servis AC Mobil pada ANDROMEDA ini menggunakan metode pengembangan sistem dan metode blackbox, yaitu dengan menguji form input data yang terdapat pada Aplikasi Pelayanan Servis AC Mobil pada ANDROMEDA. Hasil Aplikasi pelayanan servis ini pada CV.Andromeda yaitu tiga input dan empat output yang terdiri input perbaikan input pelanggan dan input transakasi sedangkan output terdiri dari laporan Perbaikan, laporan transaksi perhari dan perbulan, laporan nota, pengimputan dan laporan datadata pelayanan servis AC.Mobil Andromeda ini lebih akurat dan detil serta cepat dan efektip.
\end{abstract}

Kata Kunci: Pelayanan, Transaksi, Servis AC Mobil

\section{ABSTRACT}

Application of car air conditioner service fisher in the CV. Andromeda workshop where in the process of working this service application uses a visual basic programming language. 6.0. The method used in the Car AC Service Service Application at ANDROMEDA uses the blackbox method, namely by testing the data input form contained in the Car AC Service Service Application at ANDROMEDA. The results of this service application on CV.Andromeda are three inputs and four outputs consisting of input improvements to customer inputs and transaction inputs while the output consists of Repair reports, daily and monthly transaction reports, memorandum reports, compilation and AC service report data reports. This Andromeda car is more accurate and detailed as well as fast and effective.

Keywords: Services, Transactions, AC Services Car

\section{Pendahuluan}

Di era globalisasi ini ilmu komputer maupun kebutuhan manusia yang ingin praktis terutama dalam mengolah data laporan yang akurat maka saat ini di dunia usaha [1]. Software dan hardware dan Alat komputer dimana dengan teknologi komputer saat ini tidak hanya digunakan oleh kalangan tertentu saja, perusahaan dalam berbisnis, pemerintahan, instansi, pendidikan maupun lembaga kursus, saat ini komputer berkapasitas tinggi dan interaksi pengguna dalam mengelola sangat tidak sulit apalagi dalam mengelola data Jasa servis [2]. ANDROMEDA AC bengkulu salah satu bentuk usaha jasa layanan yang bergerak dalam Pelayanan
Servis AC mobil dimana pelayanan datang langsung kekantor ANDROMEDA AC bengkulu untuk servis AC mobil. Pelayanan yang ada di daerah kota bengkulu. Semakin banyaknya servis AC mobil yang dibutuhkan Pelayanan maka ANDROMEDA AC Bengkulu agar laporan dan data yang masih dicatat pada buku catatan (Notabook) serta untuk mendapatkan hasil yang maksimal, peneliti menilai dalam pengolahan data Pelayanan ini, dimana dalam data-data Pelayanan yang didapat masih manual, data jasa servis AC mobil tidak otomatis proses secara sistem yang cepat dalam mengolah data Pelayanan. Dengan adanya penelitian ini penulis bersaman pihak ANDROMEDA AC Bengkulu ingin merancang sebuah 
rancangan aplikasi layanan servis AC[3] mobil Pengolahan Data jasa layanan ini Menggunakan Bahasa Pemrograman Visual Basic 6.0 [4] ini lebih cepat dan efisien untuk kemajuan kedepannya [5]. Dengan melihat kondisi jasa layanan servis AC mobil ini maka peneliti mencoba menawarkan sebuah rancangan pembuatan aplikasi layanan servis AC Mobil.

\section{Metode Penelitian}

Metode penelitian digunakan metode pengembangan sistem dan Metode yang dilakukan pada Aplikasi Pelayanan Servis AC Mobil pada ANDROMEDA ini menggunakan metode blackbox, yaitu dengan menguji form input data yang terdapat pada Aplikasi Pelayanan Servis AC Mobil pada ANDROMEDA dan Uji kelayakan sistem menggunakan angket yang diberikan kepada sampel yang telah ditentukan. Kategori penilaian dibagi menjadi 5 (lima) aspek, yaitu penilaian terhadap tampilan, kemudahan pengguna, kinerja sistem, keamanan dan ketelitian dan isi dari sistem ini.

\section{Hasil dan Pengujian}

Setelah tahap implementasi dilakukan menggunakan Bahasa Pemrograman Visual Basic 6.0.Pada bab ini dijelaskan dan ditunjukkan hasil dan pembahasan pembuatan aplikasi pelayanan servis AC Mobil pada ANDROMEDA AC bengkulu menggunakan Visual Basic 6.0.

Pada sub bab ini, akan dijelaskan satu persatu hasil dari implementasi aplikasi pelayanan servis AC Mobil pada ANDROMEDA AC bengkulu dengan Visual Basic 6.0.

\section{Menu Login}

Menu login merupakan tampilan yang terdiri dari field user name dan field password, dengan mengetikan admin pada kolom user name dan 12345 pada kolom password dengan benar maka akan ditampilkan menu utama aplikasi pelayanan servis AC Mobil pada ANDROMEDA AC
Bengkulu Menggunakan Visual Basic 6.0. Tampilan menu login.

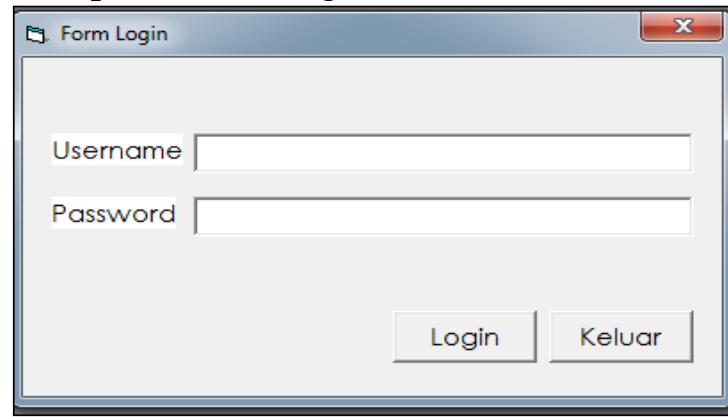

Gambar 1. Menu Login

\section{Menu Utama}

Aplikasi pelayanan servis AC Mobil pada ANDROMEDA AC bengkulu dengan Visual Basic 6.0, disusun dalam sebuah menu utama yang di bagi menjadi beberapa menu serta beberapa sub menu. Dimana menu yang ada dari gambar dibawah ini adalah Menu Admin, Menu Input Data, Menu Laporan dan Menu Keluar. Tampilan Menu utama.

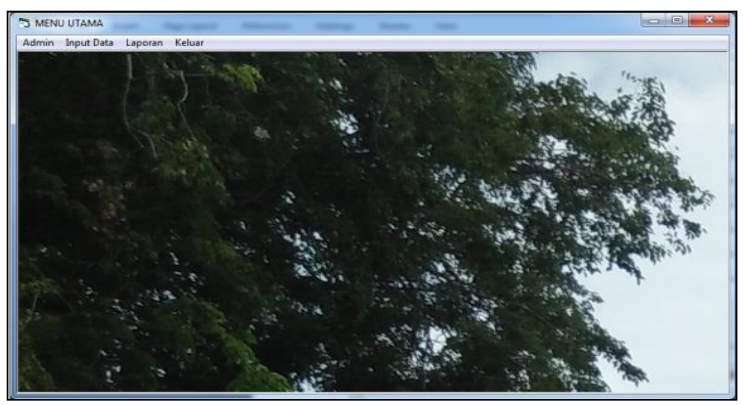

Gambar 2. Menu Utama

\section{Input Admin}

Tampilan menu input admin dimana tampilan ini digunakan untuk merobah pengguna sebagai admin yang terdiri username dan pasword dan tombol tambah, simpan, koreksi, hapus, batal dan keluar

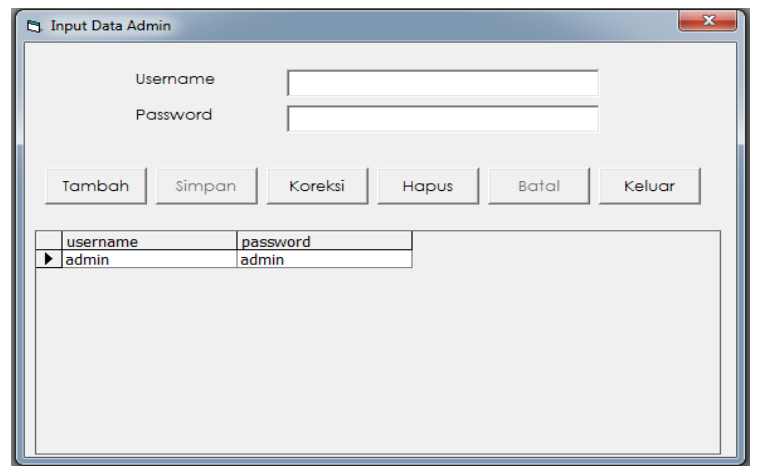

Gambar 3. Input Admin 


\section{Input Perbaikan}

Tampilan menu input data perbaikan dimana tampilan ini digunakan untuk mengimput data perbaikan dimana terdapat tombol tambah, simpan, koreksi,hapus, batal dan keluar

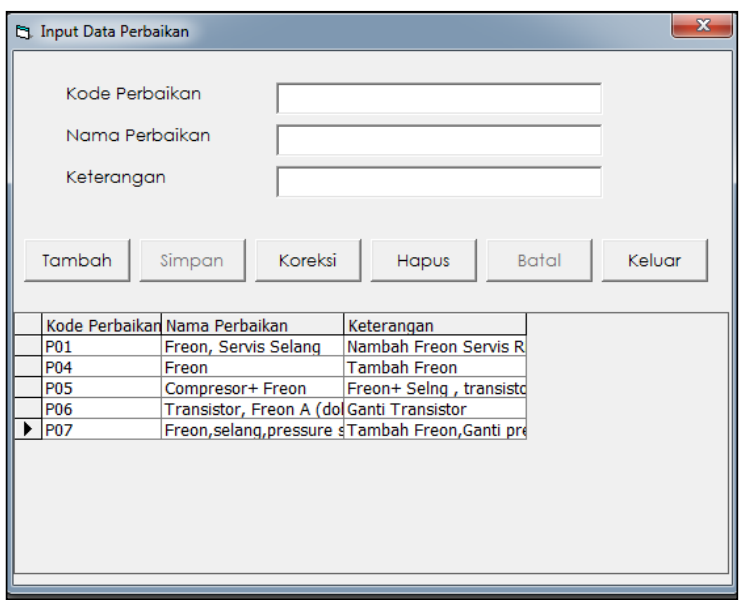

Gambar 4. Input Perbaikan

\section{Input Pelanggan}

Tampilan input data pelanggan ini digunakan untuk mengimput data pelanggan yang mana terdapat tombol tambah untuk data perbaikan, tombol simpan untuk menyimpan data pelanggan, tombol koreksi digunakan koreksi data pelanggan yang salah, tombol hapus untuk menghapus data pelanggan, tobol batal untuk membatali dan tobol keluar untuk keluar dri input data pelanggan

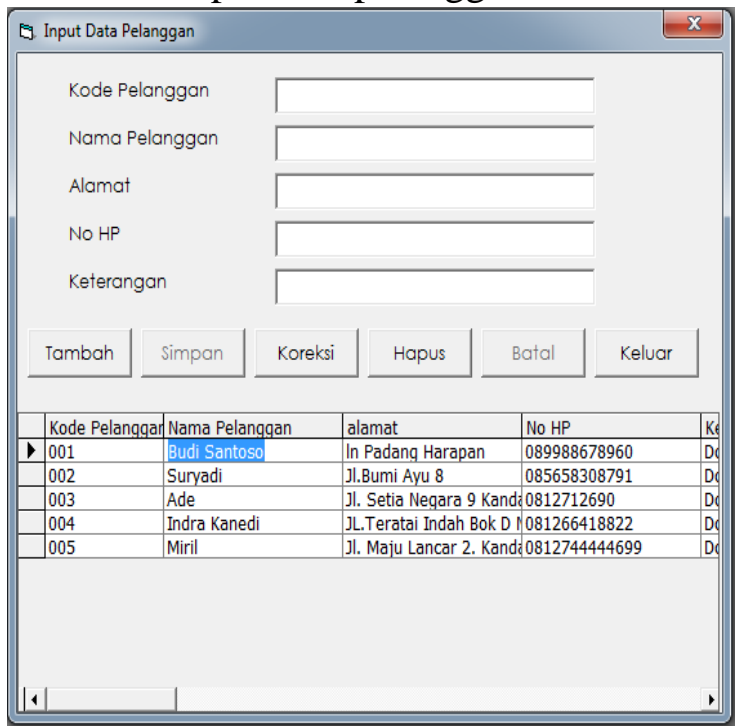

Gambar 5. Input Pelanggan
Tampilan menu input data transaksi dimana tampilan ini digunakan untuk mengimput data transaksi dimana terdapat tombol tambah, simpan, koreksi,hapus, batal dan keluar

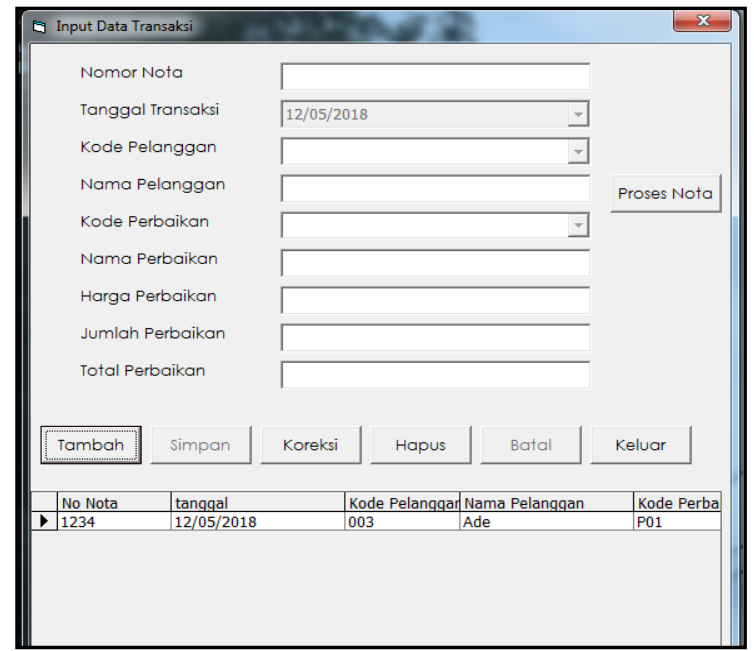

Gambar 6. Input Transaksi

\section{Laporan Perbaikan}

Tampilan menu input data Perbaikan dimana tampilan ini digunakan untuk mengimput data Perbaikan dimana terdapat tombol tambah, simpan, koreksi,hapus, batal dan keluar.

\begin{tabular}{|c|c|c|c|c|}
\hline \multicolumn{5}{|c|}{ ANDROMEDAAC } \\
\hline \multicolumn{5}{|c|}{ LAPORAN PERBAIKAN } \\
\hline No & Kode Perbaikan & Nama Perbaikan & Harga Perbaikan & Keterangan \\
\hline 1 & P01 & Freon, Servis Selang & Rp. 100.000 & Nambah Freon Servis Ringan \\
\hline 2 & P02 & Freon & Rp. 150.000 & Tamabah Freon \\
\hline 3 & P03 & Silbodi +Sil Kaki & Rp. 250.000 & Ganti Sil Bodi Sil Kaki \\
\hline 4 & P04 & Freon & Rp. 145.000 & Tambah Freon \\
\hline 5 & P05 & \begin{tabular}{|l} 
Compresort Freon \\
\end{tabular} & Rp. 300.000 & $\begin{array}{l}\text { Freon+ Selng, transistor Ganti } \\
\text { baru, }\end{array}$ \\
\hline 6 & P06 & Transistor, Freon A (doble) & Rp. 425.000 & Ganti Transistor \\
\hline 7 & P07 & Freon,sel ang:pressure switch & Rp. 250.000 & $\begin{array}{l}\text { Tambah Freon,G anti pressure } \\
\text { switch }\end{array}$ \\
\hline & & & & $\begin{array}{l}\text { Sengkulu, 13-Mei-2018 } \\
\text { impinan Andromeda }\end{array}$ \\
\hline
\end{tabular}

\section{Gambar 7. Laporan Perbaikan}

\section{Laporan Transaksi Perhari}

Tampilan laporan transaksi perhari dimana tampilan ini digunakan untuk laporan data transaksi perhari.

\section{Input Transaksi}




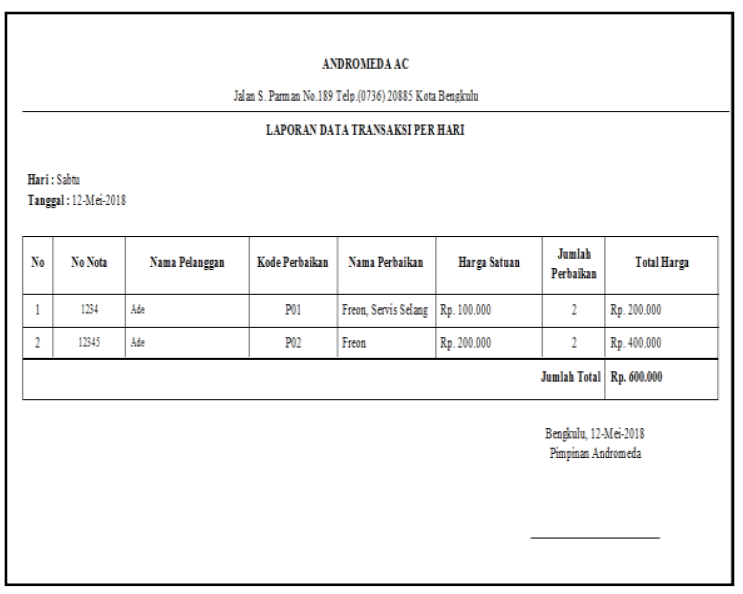

Gambar 8. Laporan Transaksi Perhari

\section{Laporan Transaksi Perbulan}

Tampilan laporan transaksi perbulan dimana tampilan ini digunakan untuk laporan transaksi perbulan.

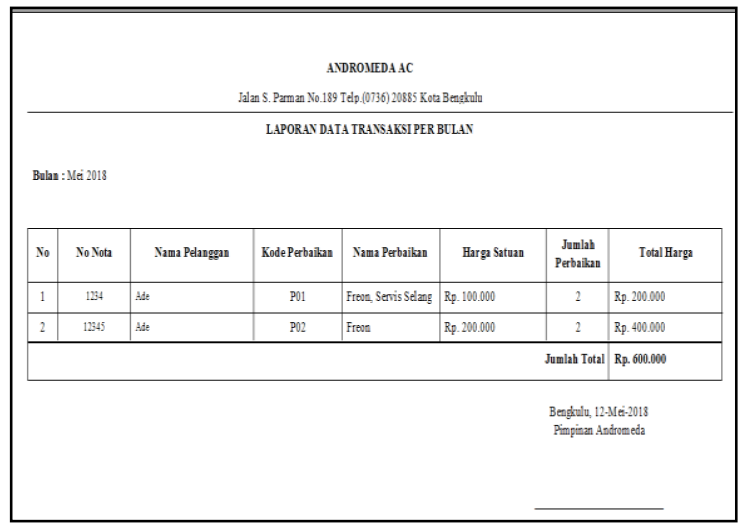

Gambar 9. Laporan Transaksi Perbulan

\section{Laporan Nota}

Tampilan laporan nota dimana tampilan ini digunakan untuk Nota dimana sebagai bukti transakasi

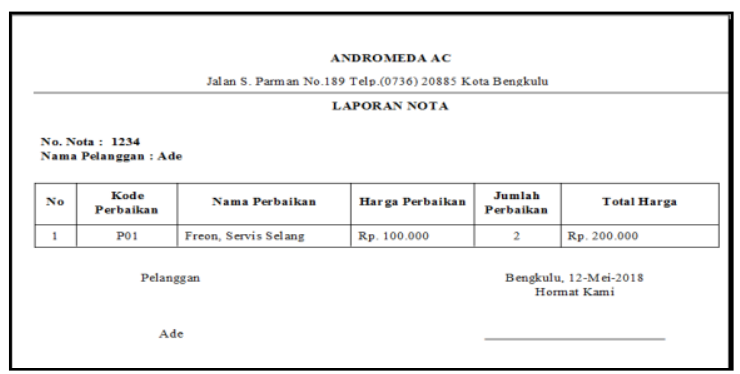

Gambar 10. Laporan Nota

\section{Keluar Aplikasi}

Tampilan keluar ini aplikasi Pelayanan Servis AC Mobil ANROMEDA. Terdapat tombol yes keluar dari aplikasi dan tombol no batal keluar.

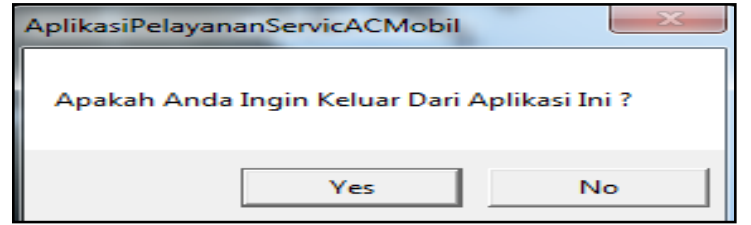

Gambar 11. Keluar Aplikasi

\section{Pengujian Sistem}

Pengujian sistem dilakukan dengan menggunakan metode blackbox, yaitu dengan menguji form input data yang terdapat pada Aplikasi Pelayanan Servis AC Mobil pada ANDROMEDA. Pengujian yang dilakukan antara lain :

\section{Metode Blackbox}

Adapun hasil pengujian dengan menggunakan metode blackbox yang penulis lakukan.

Tabel 1. Hasil Pengujian Tes Program

\begin{tabular}{|c|c|c|c|}
\hline No & $\begin{array}{c}\text { Skenario } \\
\text { Pengujian }\end{array}$ & Test Case & $\begin{array}{c}\text { Hasil } \\
\text { Pengujian }\end{array}$ \\
\hline 1. & $\begin{array}{l}\text { Mengosongkan } \\
\text { semua isian data } \\
\text { pada form login, lalu } \\
\text { klik tombol login }\end{array}$ & $\begin{array}{l}\text { Username : } \\
\text { "” } \\
\text { Password : } \\
\text { “" }\end{array}$ & $\begin{array}{l}\text { Sistem menolak } \\
\text { akses login dan } \\
\text { tidak } \\
\text { memunculkan } \\
\text { menu utama } \\
\text { disertai dengan } \\
\text { pesan kesalahan }\end{array}$ \\
\hline 2 & $\begin{array}{l}\text { Mengosongkan isian } \\
\text { data password pada } \\
\text { formlogin, lalu klik } \\
\text { tombol login }\end{array}$ & $\begin{array}{l}\text { Username : } \\
\text { "admin" } \\
\text { Password : } \\
\text { ", }\end{array}$ & $\begin{array}{l}\text { Sistem menolak } \\
\text { akses login dan } \\
\text { tidak } \\
\text { memunculkan } \\
\text { menu utama } \\
\text { disertai dengan } \\
\text { pesan kesalahan }\end{array}$ \\
\hline 3 & $\begin{array}{l}\text { Mengosongkan isian } \\
\text { data username pada } \\
\text { form login, lalu klik } \\
\text { tombol login }\end{array}$ & $\begin{array}{l}\text { Username : } \\
\text { "”, } \\
\text { Password : } \\
\text { "admin" }\end{array}$ & $\begin{array}{l}\text { Sistem menolak } \\
\text { akses login dan } \\
\text { tidak } \\
\text { memunculkan } \\
\text { menu utama } \\
\text { disertai dengan } \\
\text { pesan kesalahan }\end{array}$ \\
\hline 4. & $\begin{array}{l}\text { Memasukkan isian } \\
\text { data pada form login } \\
\text { yang benar, lalu klik } \\
\text { tombol login. }\end{array}$ & $\begin{array}{l}\text { Username : } \\
\text { "admin" } \\
\text { Password : } \\
\text { "admin" }\end{array}$ & $\begin{array}{l}\text { Sistem } \\
\text { menerima akses } \\
\text { login dan } \\
\text { memunculkan } \\
\text { menu utama } \\
\text { disertai dengan } \\
\text { pesan "Berhasil } \\
\text { Login", }\end{array}$ \\
\hline 5 & $\begin{array}{l}\text { Memasukkan isian } \\
\text { data pada form login } \\
\text { yang salah, lalu klik } \\
\text { tombol login. }\end{array}$ & $\begin{array}{l}\text { Username : } \\
\text { "admin" } \\
\text { Password : } \\
\text { "12345" }\end{array}$ & $\begin{array}{l}\text { Sistem menolak } \\
\text { akses login dan } \\
\text { tidak } \\
\text { memunculkan } \\
\text { menu utama } \\
\text { disertai dengan } \\
\text { pesan "Gagal } \\
\text { Login", }\end{array}$ \\
\hline 6 & 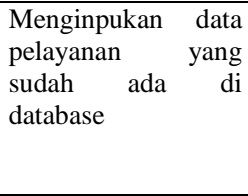 & $\begin{array}{l}\text { Pelayanan } \\
\text { Servis sama }\end{array}$ & $\begin{array}{l}\text { Sistem Menolak } \\
\text { Untuk } \\
\text { menyimpan } \\
\text { data disertai } \\
\text { dengan pesan } \\
\text { kesalahan }\end{array}$ \\
\hline
\end{tabular}




\section{Pengetesan Kotak Hitam (Black Boxt Test)}

Demo ini dilakuan oleh pembimbing dan karyawan pada ANDROMEDA AC Pengetesan dilakukan dengan cara menjalankan program yaitu dengan memasukkan data-data yang berhubungan dengan data Perbaikan. Adapun data-data yang dimasukkan berupa data admin, data perbaikan, data pelanggan data transakasi, Berdasarkan uji coba mendeteksi trouble windows telah, penginputan maupun pemasukan data dan output dapat berjalan dengan baik.

Uji kelayakan sistem menggunakan angket yang diberikan kepada sampel yang telah ditentukan. Kategori penilaian dibagi menjadi 5 (lima) aspek, yaitu penilaian terhadap tampilan, kemudahan pengguna, kinerja sistem, keamanan dan ketelitian dan isi dari sistem ini.

Tabel.2. Hasil Pengujian Sistem

\begin{tabular}{|c|l|c|c|c|}
\hline \multirow{2}{*}{} & \multirow{2}{*}{ Bagian Yang Diuji } & \multicolumn{3}{|c|}{ Hasil Pengujian } \\
\hline & & Kurang & Cukup & Baik \\
\hline 1 & Tampilan Program & & & $\checkmark$ \\
\hline 2 & Kemudahan Pengguna & & & $\checkmark$ \\
\hline 3 & Kerja Sistem dan & & & $\checkmark$ \\
\hline 4 & $\begin{array}{l}\text { Keamanan } \\
\text { Ketelitian }\end{array}$ & & & $\checkmark$ \\
\hline 5 & Isi Program & & & $\checkmark$ \\
\hline
\end{tabular}

\section{Tanggapan Responden Tentang Penggunaan Sistem}

Pengujian melibatkan responden sebanyak 10 (sepuluh) orang dengan mengisi kuisioner pengujian. Terdapat 5 (lima) item pertanyaan yang diberikan dan 3 (tiga) pilihan jawaban. Adapun hasil dari jawaban responden mengenai sistem yang dibuat oleh penulis dapat digambarkan dalam table hasil secara global (keseluruhan). Sedangkan untuk rincian jawaban responden dapat dilihat di bagian lampiran penelitian ini.

Tabel 3. Responden Keseluruhan

\begin{tabular}{|c|c|c|c|c|}
\hline \multirow{2}{*}{ No. } & \multirow{2}{*}{ Pertanyaan } & \multicolumn{3}{|c|}{ Jawaban } \\
\hline & & Baik & Cukup & Kurang \\
\hline 1 & $\begin{array}{lr}\text { Apakah } & \text { tampilan } \\
\text { dari } & \text { aplikasi } \\
\text { Pelayanan } & \text { Servis } \\
\text { AC } & \text { Mobil } \\
\text { ANDROMEDA } \\
\text { ini } & \text { terlihat }\end{array}$ & 8 & 1 & 1 \\
\hline
\end{tabular}

\begin{tabular}{|c|c|c|c|c|}
\hline & menarik? & & & \\
\hline 2 & $\begin{array}{lr}\text { Apakah } & \text { dengan } \\
\text { adanya aplikasi } \\
\text { ini }\end{array}$ & 8 & 2 & 0 \\
\hline 3 & $\begin{array}{l}\text { Apakah program } \\
\text { ini dibuat telah } \\
\text { sesuai dengan } \\
\text { kebutuhan pada } \\
\text { Kantor } \\
\text { ANDROMEDA } \\
\text { AC? }\end{array}$ & 8 & 1 & 1 \\
\hline 4 & $\begin{array}{lr}\text { Setujukah } & \text { Anda } \\
\text { apabila } & \text { program } \\
\text { ini } & \text { digunakan } \\
\text { pada } & \text { bagian } \\
\text { Pelayanan } & \text { Servis } \\
\text { AC } & \text { Mobil } \\
\text { ANDROMEDA? }\end{array}$ & 9 & 0 & 1 \\
\hline 5 & $\begin{array}{lr}\text { Apakah } & \text { hasil } \\
\text { sistem } & \text { ini } \\
\text { membantu } & \text { dalam } \\
\text { Pelayanan } & \text { Servis } \\
\text { AC } & \text { Mobil } \\
\text { ANDROMEDA } \\
\text { yang memuaskan } \\
\text { ? }\end{array}$ & 10 & 0 & 0 \\
\hline & Jumlah & 43 & 4 & 3 \\
\hline
\end{tabular}

Berdasarkan hasil yang diperoleh dari jawaban responden.

$$
\begin{array}{ll}
\text { Baik }= & \frac{43}{50} \times 100=86 \% \\
\text { Cukup }= & \frac{4}{50} \times 100=8 \% \\
\text { Kurang }= & \frac{3}{50} \times 100=6 \%
\end{array}
$$

Dari hasil persentasi tersebut dapat dibuat diagram penilaian berupa grafik penilaian seperti terlihat pada gambar dibawah ini:

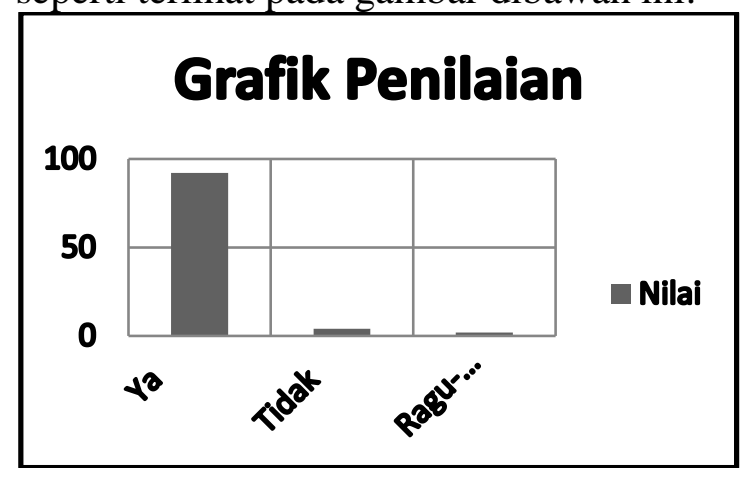

\section{Gambar 12. Grafik Penilaian}

Berdasarkan hasil yang diperoleh dari jawaban responden yang terlihat gambar 
4.14. grafik penilain diatas, dapat di ambil kesimpulan bahwa sistem ini layak untuk digunakan dan diterapkan pada bagian Aplikasi pelayanan servis AC Mobil Andromeda bengkulu.

\section{Kesimpulan}

Dalam pembuatan Aplikasi Pelayanan Servis AC Mobil ANDROMEDA ini Menggunakan Visual Basic.6.0 dapat disimpulkan sebagai berikut :

1. Dalam proses kerja Aplikasi Pelayanan Servis AC Mobil ANDROMEDA Menggunakan Visual Basic.6.0, dimana pengimputan data-data perbaikan ini lebih akurat dan detil serta cepat dan efektip.

2. Aplikasi Pelayanan Servis AC Mobil ANDROMEDA ini menampilkan dan didukung oleh bahasa pemrograman visual basi 6.0.

3. Penyimpanan data dalam bentuk database dapat membantu mempermudah proses pencarian data tentang laporan Pelayanan Servis AC Mobil ANDROMEDA dapat lebih lengkap dan tertata rapi..

\section{Saran}

Adapun saran-saran yang dapat penulis kemukakan disini adalah :

1. Aplikasi yang baru ini hendaknya dapat dijadikan sebagai dasar untuk memperbaiki sistem yang lama yang masih manual.
2. Perubahan aplikasi sebaiknya dilakukan secara bertahap, sehingga apabila ada kekurangan dapat disesuaikan lebih lanjut dikemudian hari.

3. Pelayanan Servis AC Mobil ANDROMEDA hendaknya diopreasikan oleh user yang memahami tentang aplikasi agar perintah dan pengisiannya lebih tepat dan terhindar dari kesalahan.

\section{Daftar Pustaka}

[1]Anshory, S. (2010). Analisis dan Perancangan Sistem Informasi Customer Relathionship Management Pada Lembaga Bahasa Inggris Fist Yogyakarta. Gadjah Mada.

[2]Kurniawan, Andry, 2013. Rekayasa Perangkat Lunak Aplikasi Penjualan Pada Toko Story Time Factory Outlet Menggunakan Pemrograman Java. Program Studi Sistem Komputer Fakultas Teknologi Informasi. Universitas Andalas.

[3]Prasetya, H. (2009) Pengujian untuk kerja AC domestik dengan refrigerant $\mathrm{R}$ 22 dan HCR-22 pada variasi beban pendinginan evaporator dan laju dingin kondesor. Surakarta

[4]Suryanto Thabrani, 2007, Mudah dan Cepat Menguasai Visual Basic, Media Kita, Jakarta Selatan, 120 halaman.

[5]Tjiptono, Fandy. (2011) Servis, Quality and Satisfaction (ed.3) Yogyakarta. Andi 